\title{
Cross-Sectional Prevalence of SARS-CoV-2 Among Skilled Nursing Facility Employees and Residents Across Facilities in Seattle
}

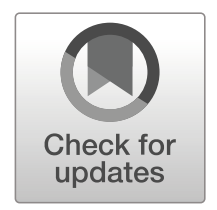

\author{
Ana A. Weil, MD, MPH' (1), Kira L. Newman, MD, PhD ${ }^{7}$, Thuan D. Ong, $M D^{7}$, \\ Giana H. Davidson, $M D, M P H^{2,3}$, Jennifer Logue, $B S^{7}$, Elisabeth Brandstetter, $M P H^{7}$, \\ Ariana Magedson, BS ${ }^{7}$, Dylan McDonald, BS ${ }^{7}$, Denise J. McCulloch, MD', \\ Santiago Neme, $M D^{7}$, James Lewis, MD, MPH' , Jeff S. Duchin, MD ${ }^{1,4}$, Weizhi Zhong, $B S^{5}$, \\ Lea M. Starita, $P h D^{5,6}$, Trevor Bedford, $P h D^{6,7}$, Alison C. Roxby, MD, MSc ${ }^{1,8}$, and \\ Helen Y. Chu, MD, MPH
}

\begin{abstract}
'Department of Medicine, Division of Allergy and Infectious Diseases, University of Washington, Seattle, WA, USA; ${ }^{2}$ Department of Surgery, University of Washington, Seattle, WA, USA; ${ }^{3}$ Department of Health Services, University of Washington, Seattle, WA, USA; ${ }^{4}$ Public Health - Seattle \& King County, King County, WA, USA; ${ }^{5}$ Department of Genome Sciences, University of Washington, Seattle, WA, USA; 'Brotman Baty Institute for Precision Medicine, Seattle, WA, USA; ${ }^{7}$ Fred Hutchinson Cancer Research Center, Seattle, WA, USA; ${ }^{8}$ Department of Global Health, University of Washington, Seattle, WA, USA.
\end{abstract}

BACKGROUND: Skilled nursing facilities (SNFs) are highrisk settings for SARS-CoV-2 transmission. Infection rates among employees are infrequently described.

OBJECTIVE: To describe SARS-CoV-2 rates among SNF employees and residents during a non-outbreak time period, we measured cross-sectional SARS-CoV-2 prevalence across multiple sites in the Seattle area.

DESIGN: SARS-CoV-2 testing was performed for SNF employees and residents using quantitative real-time reverse transcription polymerase chain reaction. A subset of employees completed a sociodemographic and symptom questionnaire.

PARTICIPANTS: Between March 29 and May 13, 2020, we tested 1583 employees and 1208 residents at 16 SNFs for SARS-CoV-2.

MAIN MEASURE: SARS-CoV-2 testing results and symptom report among employees and residents.

KEY RESULTS: Eleven of the 16 SNFs had one or more resident or employee test positive. Overall, $46(2.9 \%)$ employees had positive or inconclusive testing for SARSCoV-2, and among those who completed surveys, most were asymptomatic and involved in direct patient care. The majority of employees tested were female (934, $73 \%$ ), and most employees were Asian (392, 30\%), Black $(360,28 \%)$, or white $(360,28 \%)$. Among the 1208 residents tested, $110(9.1 \%)$ had positive or inconclusive results. There was no association between the presence of positive residents and positive employees within a SNF ( $p=0.62$, McNemar's test).

CONCLUSIONS: In the largest study of SNFs to date, SARS-CoV-2 infections were detected among both employees and residents. Employees testing positive were

Electronic supplementary material The online version of this article (https://doi.org/10.1007/s11606-020-06165-7) contains supplementary material, which is available to authorized users.

Received August 5, 2020

Accepted August 14, 2020

Published online September 1, 2020 often asymptomatic and involved in direct patient care. Surveillance testing is needed for SNF employees and residents during the pandemic response.

KEY WORDS: SARS-CoV-2; skilled nursing facility.

$\mathrm{J}$ Gen Intern Med 35(1 1):3302-7

DOI: $10.1007 / \mathrm{s} 11606-020-06165-7$

(C) The Author(s) 2020

\section{INTRODUCTION}

Skilled nursing facilities (SNFs) are high-risk settings for rapid spread of SARS-CoV-2 infection because they are congregate settings that frequently house a vulnerable patient population with multiple co-morbidities. ${ }^{1,2}$ Many outbreaks in long-term care facilities have been described, often with high mortality rates in residents. ${ }^{3}$ Symptom screening alone for COVID-19 has been shown to be inadequate for preventing outbreaks in congregate settings, likely because of asymptomatic and presymptomatic spread. ${ }^{4}$ For this reason, the Centers for Medicaid and Medicare Services released guidance recommending baseline screening for SARS-CoV-2 in congregate settings and periodic screening of employees and residents. ${ }^{5}$ Given the essential role of SNF employees and their potential role in introducing SARS-CoV-2 into a high-risk setting, the prevalence of SARS-CoV-2 in SNF personnel is key to understanding outbreaks and disease transmission within SNFs.

The SNF care environment and SNF employees have specific characteristics that increase the risk of SARS-CoV-2 outbreaks in SNFs. The COVID-19 pandemic has accentuated realities of the SNF care environment in which resources and personnel are often inadequate to meet the demands of an infectious disease outbreak, and SNFs have also reported employee and supply shortages since the COVID-19 
pandemic began. ${ }^{6}$ SNF employees also frequently work at multiple sites, experience higher turnover, receive lower pay compared with acute care settings, have less access to SARSCoV-2 testing, and have been less prioritized to receive personal protective equipment (PPE) allocations. ${ }^{7-11} \mathrm{~A}$ recent account in our state describes SNF employees demonstrating heterogeneous PPE use and training, in addition to inadequate PPE supply and delayed recognition of cases. ${ }^{12}$ Due to fear of infection and/or lack of PPE, absenteeism in the SNF environment has also been reported. ${ }^{13,14}$ Prior to the COVID-19 era, high levels of absenteeism in nursing facilities have been associated with poor outcomes. ${ }^{15}$

In Washington State, a government call to action on March 10, 2020, led to SNFs barring visitors and engaging in employee symptom-based screening. ${ }^{16}$ Despite these precautions, cases of SARS-CoV-2 continue to be observed in SNFs. To address this, testing for SARS-CoV-2 among SNF employees regardless of symptoms is needed in order to develop strategies for decreasing transmission in SNFs and the larger community. In this study, we describe the results of cross-sectional resident and employee SARS-CoV-2 testing, and infection control and personnel policies associated with 16 Seattle area SNFs.

\section{METHODS}

Through two testing strategies, a total of 16 SNFs offered testing to either residents, employees, or both. The first testing strategy was directed by Public Health of Seattle \& King County (PHSKC) and focused on SNF resident testing with employee testing offered at select sites. The second testing strategy was facilitated by the Seattle Flu Study (SFS) and directed at testing only employees. PHSKC testing was conducted by providers from University of Washington, between March 29, 2020, and May 8, 2020, at 13 SNFs and one assisted living facility, of which six offered both resident and employee testing and eight had only resident testing. Employee testing by SFS was designed to coincide with resident testing done by PHSKC when possible. SFS testing was conducted between April 14, 2020, and May 13, 2020, at 13 SNFs. At three SNFs, both the PHSKC and Seattle Flu Study teams tested SNF employees.

\section{Population}

PHSKC identified SNFs in need of SARS-CoV-2 testing, including sites with known COVID-19 cases, facilities with no known cases, or where COVID-19 testing of residents had not occurred. For testing through PHSKC, teams of healthcare workers collected nasopharyngeal (NP) swabs from all residents in a SNF during a single visit. For testing through Seattle Flu Study, facilities identified by PHSKC were contacted by the study team for employee testing. Facilities agreeing to participate messaged all employees before the visit to inform them of the upcoming testing event and distributed a copy of the informed consent form for previewing. Employees were eligible to participate if they worked at the facility and were over 18 years old. All testing was voluntary and not required by the employer, and employees were advised that results would not be reported directly to employers. Employees who reported prior testing for SARS-CoV-2 through other mechanisms were eligible for enrollment. Study staff consented individuals in English or in the participant's language of preference using an interpreter. After informed consent was obtained, individuals completed an electronic tablet-based questionnaire (Project Redcap in REDCap, Nashville, TN) and self-collected a mid-nasal swab under observation by trained study staff.

\section{Laboratory Methods}

For testing through PHSKC, NP swabs from SNF residents were placed in universal viral transport media (Becton Dickinson, Franklin, NJ) and transported to the University of Washington Virology Laboratory for testing via a one-step real-time reverse transcription polymerase chain reaction (RTPCR) assay following the SARS-CoV-2 CDC assay protocol, as previously described. ${ }^{17}$ No samples tested through PHSKC were resulted as indeterminant.

For testing through Seattle Flu Study, self-collected midnasal nylon-flocked swabs were placed in universal viral transport media (Becton Dickinson, Franklin, NJ) and transported to the Brotman Baty Institute for Precision Medicine and the Northwest Genomics Center for testing using a laboratory-developed test for SARS-CoV-2, as previously described. ${ }^{18}$ Briefly, SARS-CoV-2 detection was performed using real-time RT-PCR with a probe set targeting Orflb and S with FAM fluor (Life Technologies 4332079 assays \# APGZJKF and APXGVC4APX) multiplexed with an RNase $\mathrm{P}$ probe set with VIC or HEX fluor (Life Technologies A30064 or Integrated Data Technologies custom made) each in duplicate on a QuantStudio 6 instrument (Applied Biosystems). Three or four replicates for RNase P and SARS-CoV-2 were required to have a detection cycle threshold less than 40 for a sample to be considered positive for this laboratory-developed test, or both replicates must be positive in the research assay. Samples resulting with two replicates of positive SARS-CoV-2 detection were defined as inconclusive. Because tests determined to be inconclusive had SARS-CoV2 detected in multiple replicates, these results were grouped with positive results for reporting purposes.

\section{Data Collection}

For individuals tested through PHSKC, data available included name, date of birth, date of testing, and whether the individual was a resident or an employee. For employees tested through the Seattle Flu Study, data included participant date of birth, date of testing, race and ethnicity, location and nature of work, new symptoms experienced during the last 7 days, and history of SARS-CoV-2 testing (Appendix 1 in the 
Supplementary Material). Information on SNF policies regarding absenteeism, infection control, and employee health were collected from SNF management by email 2 weeks following employee testing using a standardized data collection form (Appendix 2 in the Supplementary Material).

\section{Data Analysis}

Time between resident and employee testing was calculated as the days elapsed between first testing dates for each group at a SNF. For sites with multiple testing dates for employees, residents, or both, tests from all dates for a given group were combined to calculate the prevalence at each site. All data analysis was conducted in the R statistical language (R Foundation for Statistical Computing, Vienna, Austria). Frequencies were tabulated for social and demographic data. To test the association between residents and employees who tested positive for SARS-CoV-2, a two-tailed McNemar's test was used. $p$ values $<0.05$ were considered statistically significant.

\section{Reporting}

For employees, positive or inconclusive SARS-CoV-2 test results were reported directly to participants by phone within $48 \mathrm{~h}$ and to the Washington State Department of Health. Resident results were reported to the ordering physician at the SNF.

\section{Ethics}

The Seattle Flu Study was approved by the University of Washington Institutional Review Board. Other testing of residents and employees was conducted as a public health surveillance activity under the direction of PHSKC.

\section{RESULTS}

\section{Employee Testing Results}

Overall, 1583 employees at 16 SNFs were tested, with 287 (18\%) tested through PHSKC and 1296 (82\%) through SFS. A total of 46 (2.9\%) employees had positive or inconclusive testing for SARS-CoV-2 (Fig. 1; Supplemental Table 1). Demographic information from employees tested through SFS is shown in Table 1. This information is not available for employees tested through PHSKC. The majority of employees tested were female $(934,72 \%)$ and identified their race as Asian $(392,30 \%)$, Black $(360,28 \%)$, or white $(360,28 \%)$, and worked in direct patient care $(795,62 \%)$. Only $8.1 \%$ (105) of employees reported working at more than one SNF. New symptoms were reported in $8.7 \%$ (106) during the week prior to testing. Most employees $(930,73 \%)$ had not previously been tested for SARS-CoV-2. Of employees who reported prior testing, $13 \%$ (46) had a previous positive or inconclusive test result.

Of the 46 total employees who tested positive for SARS$\mathrm{CoV}-2,33$ were tested through the PHSKC and 13 through SFS, and only the latter 13 had accompanying survey data.
The majority of those tested through SFS reported performing direct patient care (Table 1). Employees who tested positive were more likely to have had a prior positive test compared with employees that tested negative (6 (46\%) versus 40 (3\%), respectively). Employees who tested positive were less likely to be asymptomatic (9 (69\%) versus 1170 (92\%), respectively). Among the six individuals with SARS-CoV-2 detected who had not previously been tested, only one (14\%) reported symptoms.

Based on the employee counts provided by SNFs, an average of 70\% (range 34-108\%) of employees on-site on the day of testing participated (Supplemental Table 2). Despite facility policies that any employees with new respiratory symptoms should not come to work, several employees reported respiratory symptoms ( 2 with cough, 1 with sore throat) and tested positive in our study, and several employees reporting gastrointestinal symptoms also tested positive.

\section{Resident Testing Results}

Residents of 14 SNFs were tested through the PHSKC. Of 1208 residents, $110(9.1 \%)$ tested positive for SARS-CoV-2 (Fig. 1; Supplemental Table 1). Resident testing was conducted within an average of 1.6 days (range 0-7 days) of employee testing. Five SNFs (36\%) had SARS-CoV-2-positive residents, and among SNFs with at least one resident who tested positive, the mean positivity rate for SARS-CoV-2 was $33 \%$ (range, $3.0-70 \%$ ).

\section{Relationship Between Employees and Resident Testing Results}

Of the 14 SNFs with resident and employee testing (Fig. 1), four (29\%) had both positive residents and positive employees, three $(22 \%)$ had positive employees but no positive residents, and one (7.1\%) had positive residents but no positive employees. There was no significant association between presence of positive residents and positive employees $(p=0.62)$.

\section{Facility Policies}

Thirteen of the 16 SNFs responded to the survey (Supplemental Table 2), although only six sites completed all survey questions. All sites reported that they had a policy in place that employees with any new respiratory symptoms should not come to work, and all sites reported having paid sick leave policies. These policies varied with regard to eligibility and how leave was made available. For example, one SNF reported a paid sick leave policy that allowed employees to accrue negative sick leave if necessary, while others did not allow this option. Most SNFs reported following the Centers for Disease Control guidelines for return to work after a respiratory illness. ${ }^{19}$ Seven of the 16 SNFs reported their PPE policy and all required universal masking. The type of mask used was not specified. 


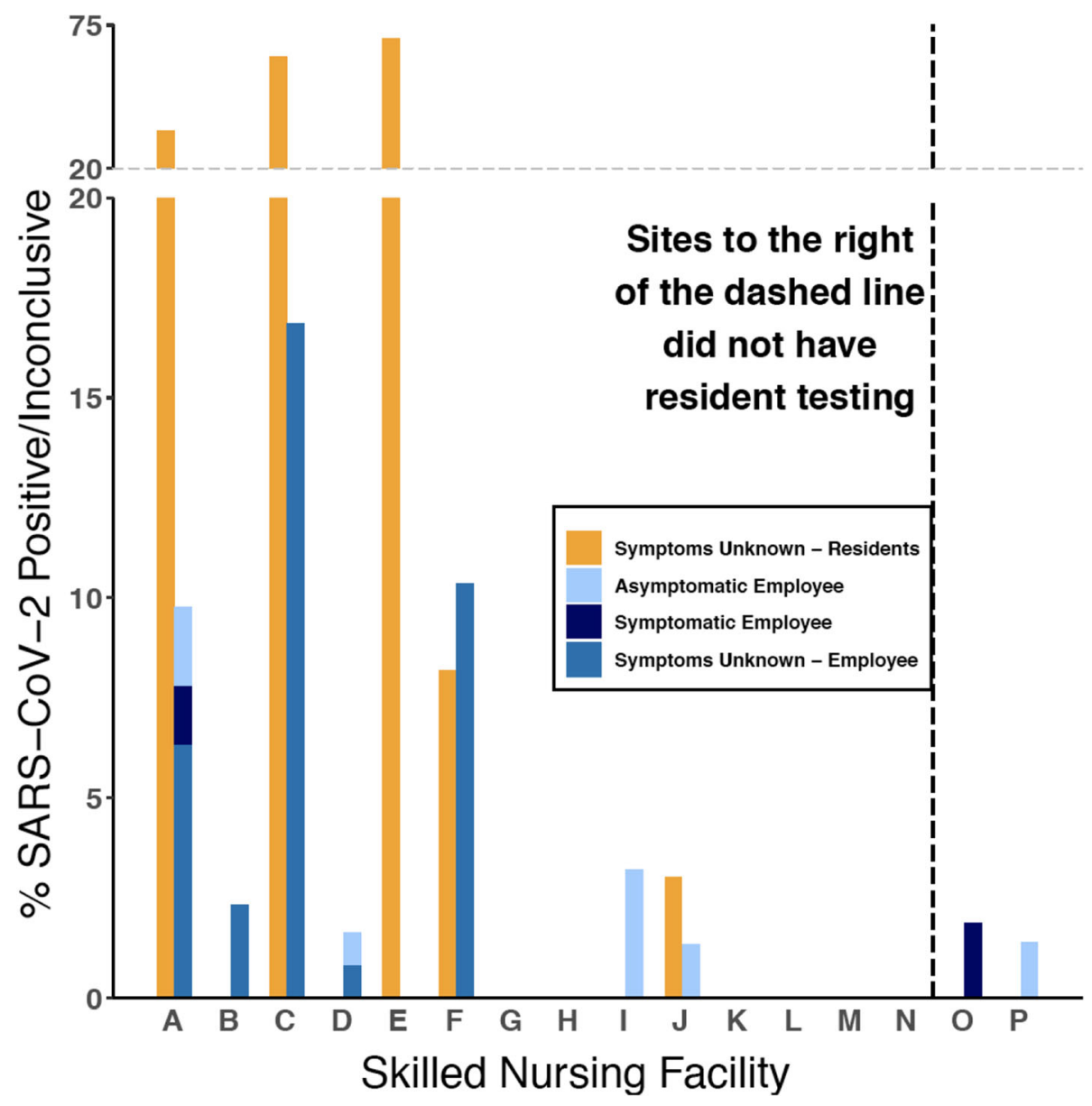

Figure 1 Proportion of positive or inconclusive test results for SARS-CoV-2 at skilled nursing facilities, stratified by residents and employees, and self-reported symptoms. Letters represent individual skilled nursing facilities. Symptomatic study participants reported at least one of the following new symptoms at time of sample collection: fever, headache, cough, chills, sweats, sore throat, nausea or vomiting, rhinorrhea, fatigue, myalgia, dyspnea, diarrhea, anosmia, or ageusia.

\section{DISCUSSION}

We report the results of a large cross-sectional study evaluating SARS-CoV-2 prevalence in skilled nursing facilities (SNFs) in the Seattle area during the spring 2020 peak of the COVID-19 pandemic. To our knowledge, this is the first study to report occupational SARS-CoV-2 for SNF workers outside of an outbreak investigation and the largest study to date evaluating prevalence of SARS-CoV-2 in SNF workers.

We detected SARS-CoV-2 in both residents and employees at multiple sites. The majority of employee testing positive for SARS-CoV-2 were asymptomatic and involved in direct patient care. In this study, all surveillance was performed starting at least 2.5 weeks after the implementation of a strict no visitor policy at SNFs throughout the region. Given that many infected SNF employees were asymptomatic, transmission events have the potential to go undetected without broad-based testing of all employees. This is critical, because asymptomatic and presymptomatic infections have led to significant transmission events in other high-density congregate living facilities with highrisk residents. ${ }^{1,4}$ Similar to other congregate environments like cruise ships, correctional institutions, and long-term care facilities, ${ }^{20-22}$ SNFs are an environment where introduction of one case may lead to rapid transmission. We did not assess for routes of disease transmission during the study period, and transmission of SARS-CoV-2 to SNF residents could have occurred from contact between residents, infected employees, or other outside contacts, such as exposure to dialysis centers outside of the SNF.

Minority communities are over-represented in low-wage healthcare clinics and include populations known to be disproportionately impacted by COVID-19. ${ }^{9,23-25} \mathrm{We}$ found that SNF employees in our study were disproportionately more non-white and non-Hispanic individuals, including a higher proportion of Asian and Black participants, than are represented in the population of the Seattle area. ${ }^{26}$ While all facilities reported some form of paid sick leave program, many had limits on eligibility for part-time and contracted employees. Lacking paid sick leave is a financial disincentive to report symptoms or positive tests. These factors highlight the vulnerability of SNF employees as an often overlooked group in the transmission of SARS-CoV-2. 
Table 1 Demographics and Clinical Characteristics of Skilled Nursing Facility Employees Tested Through Seattle Flu Study Stratified by SARS-CoV-2 Test Result

\begin{tabular}{|c|c|c|c|}
\hline & $\begin{array}{l}\text { Total, } \\
N= \\
1289\end{array}$ & $\begin{array}{l}\text { Positive/ } \\
\text { inconclusive, } \\
N=13\end{array}$ & $\begin{array}{l}\text { Negative, } \\
N=1276\end{array}$ \\
\hline $\begin{array}{l}\text { Mean age (years), } \\
\text { [range] }\end{array}$ & $\begin{array}{l}45[18, \\
83]\end{array}$ & $50[18,69]$ & $45[18,83]$ \\
\hline Female sex $(\%)$ & $934(73)$ & $10(77)$ & $924(73)$ \\
\hline Race & & & \\
\hline $\begin{array}{l}\text { American Indian/ } \\
\text { Alaska Native }\end{array}$ & $3(0.2)$ & $0(0.0)$ & $3(0.2)$ \\
\hline Asian & $392(30)$ & $4(31)$ & $388(30)$ \\
\hline Black & $360(28)$ & $3(23)$ & $357(28)$ \\
\hline Native Hawaiian/ & $34(2.6)$ & $0(0)$ & $34(2.7)$ \\
\hline \multicolumn{4}{|l|}{ Pacific Islander } \\
\hline Other/multiple & $\begin{array}{l}111 \\
(8.6)\end{array}$ & $2(15)$ & $109(8.5)$ \\
\hline White & $360(28)$ & $1(7.7)$ & $359(28)$ \\
\hline $\begin{array}{l}\text { Hispanic/Latinx } \\
\text { ethnicity }\end{array}$ & $\begin{array}{l}109 \\
(8.5)\end{array}$ & $3(23)$ & $106(8.3)$ \\
\hline \multicolumn{4}{|c|}{ Work type at enrollment facility } \\
\hline Direct patient care & $795(62)$ & $10(77)$ & $785(62)$ \\
\hline Other* & $473(37)$ & $3(23)$ & $470(37)$ \\
\hline $\begin{array}{l}\text { Employed at multiple } \\
\text { SNFs }\end{array}$ & $\begin{array}{l}105 \\
(8.2)\end{array}$ & $1(7.7)$ & $104(8.2)$ \\
\hline \multicolumn{4}{|l|}{ Symptoms } \\
\hline None & $\begin{array}{l}1179 \\
(92)\end{array}$ & $9(69)$ & $1170(92)$ \\
\hline Cough & $22(1.7)$ & $2(15)$ & $20(1.6)$ \\
\hline Sore throat & $39(3.0)$ & $1(7.7)$ & $38(3.0)$ \\
\hline Fever & $7(0.5)$ & $0(0.0)$ & $7(0.5)$ \\
\hline COVID-like illness $^{\dagger}$ & $2(0.2)$ & $0(0.0)$ & $2(0.2)$ \\
\hline $\begin{array}{l}\text { Other respiratory } \\
\text { symptoms }\end{array}$ & $40(3.1)$ & $0(0.0)$ & $40(3.1)$ \\
\hline $\begin{array}{l}\text { Gastrointestinal } \\
\text { symptoms }\end{array}$ & $12(0.9)$ & $2(15)$ & $10(0.8)$ \\
\hline $\begin{array}{l}\text { Other systemic } \\
\text { symptoms }\end{array}$ & $30(2.3)$ & $0(0.0)$ & $30(2.4)$ \\
\hline \multicolumn{4}{|c|}{ Prior SARS-CoV-2 test } \\
\hline $\begin{array}{l}\text { Positive/ } \\
\text { inconclusive }\end{array}$ & $46(3.6)$ & $6(46)$ & $40(3.1)$ \\
\hline Negative & $\begin{array}{l}309 \\
(24.0)\end{array}$ & $3(23.1)$ & $306(24.1)$ \\
\hline None & $930(72)$ & $4(31)$ & $926(73)$ \\
\hline $\begin{array}{l}\text { Days since prior test; } \\
\text { median [IQR] }\end{array}$ & $\begin{array}{l}17[10, \\
34]\end{array}$ & $17[10,17]$ & $17[11,35]$ \\
\hline $\begin{array}{l}\text { Days of work missed; } \\
\text { median [IQR] }\end{array}$ & $0[0,7]$ & $7.5[6,8]$ & $0[0,5]$ \\
\hline
\end{tabular}

Percentages may not sum to $100 \%$ due to missing responses

Other respiratory symptoms include dyspnea, rhinorrhea, anosmia, and ageusia

Gastrointestinal symptoms are defined as diarrhea, nausea, or vomiting Other systemic symptoms include chills, fatigue, myalgia, or sweats

*Non-patient care positions include administration, facilities, food service, and transportation

tCOVID-19-like illness is defined as fever and cough or shortness of breath

This study was conducted during an ongoing pandemic in Seattle. In the conduct of this study, we encountered obstacles including shortages of PPE, viral transport media, and nasal swabs. Participation was voluntary across sites, and an average of $70 \%$ on-site employees participated. The administration at each SNF presented the opportunity for testing with different levels of enthusiasm and support, and this may have impacted employee participation. Furthermore, when approached with the offer of employee testing, the administrative leadership of some of the SNFs in the Seattle area declined to participate.
Common concerns about mass employee testing from SNF administration were that testing would result in increased fear, employee absenteeism, and/or consequent staffing shortages.

Strengths of this study include broad testing of both residents and employees in a group of SNFs at the spring 2020 peak of the COVID-19 pandemic in a major metropolitan area. We collected sociodemographic and symptom data on the majority of the employees, and information on infection control policies across sites. Limitations of this study included that sites were included only if administrative leadership agreed to participate, and the sites that did not participate may have differed in infection rates and PPE practices compared with those that agreed. Testing at sites did not include all employees; only employees volunteering for testing participated. Collection of SARS-CoV-2 samples used different collection methods between residents and employees, and the timing of testing for resident and employees was not simultaneous. However, both methods of collection have proven to be concordant (Citation of a manuscript under review will be inserted here) and the mean difference between employee and resident testing was small (mean of 1.6 days). Symptom data was self-reported and may be limited by a social desirability bias and/or by recall bias. To mitigate bias, employees filled out the questionnaire using an electronic tablet while at a six foot distance from other participants, which afforded some privacy. Additionally, we do not have longitudinal data on participants and do not know how many asymptomatic individuals were presymptomatic.

As SARS-CoV-2 infections continue to cause disproportionate numbers of deaths in facilities for older adults throughout the country, strategies to prevent mortality in this fragile population are critical. We found that infections in both employees and residents persisted even with no visitor policies, and facilities had heterogenous paid leave policies. Based on our findings, implementation of periodic point prevalence testing of both residents and employees, coupled with rigorous infection control precautions and universal paid sick leave for employees, may provide an improved strategy to reduce mortality in this highly vulnerable population. Future research should focus on trials of strategies, such as routine employee testing, to understand their effectiveness in SARS-CoV-2 high-risk occupational settings.

Acknowledgments: We acknowledge the assistance of Public Health - Seattle \& King County Coronavirus testing team, which included volunteers from UW Medicine, and the many committed research assistants who made this study possible. We acknowledge the support of the Brotman Baty Institute Advanced Technology Lab and the Northwest Genomics Center. We thank the participating SNFs and their employees and residents for their cooperation and collaboration in the recruitment process. The Seattle Flu Study portion of testing was funded by Gates Ventures. The University of Washington provided material support including PPE and swabs to PHSKC for this surveillance activity.

Corresponding Author: Ana A.Helen Y. WeilChu, MD, MPH; Department of Medicine, Division of Allergy and Infectious Diseases, University of Washington, Seattle,WA, USA (e-mail: anaweil@uw. edu). 


\section{Compliance with Ethical Standards:}

Conflict of Interest: Dr. Helen Chu performs consulting services for Merck and Pfizer and has grant funding from Ellume, Cepheid, and Sanofi-Pasteur. Dr. James Lewis consults for PWN Health. Other authors have no conflicts of interest.

Disclaimer: The funder was not involved in the design of the study and does not have any ownership over the management and conduct of the study, the data, or the rights to publish.

Open Access This article is licensed under a Creative Commons Attribution 4.0 International License, which permits use, sharing, adaptation, distribution and reproduction in any medium or format, as long as you give appropriate credit to the original author(s) and the source, provide a link to the Creative Commons licence, and indicate if changes were made. The images or other third party material in this article are included in the article's Creative Commons licence, unless indicated otherwise in a credit line to the material. If material is not included in the article's Creative Commons licence and your intended use is not permitted by statutory regulation or exceeds the permitted use, you will need to obtain permission directly from the copyright holder. To view a copy of this licence, visit http://creativecommons. org/licenses/by/4.0/.

\section{REFERENCES}

1. Kimball A, Hatfield KM, Arons M, et al. Asymptomatic and presymptomatic SARS-CoV-2 infections in residents of a long-term care skilled nursing facility - King County, Washington, March 2020. MMWR Morb Mortal Wkly Rep. 2020;69(13):377-381.

2. Centers for Disease Control and Prevention, Atlanta, GA. Considerations for Preventing Spread of COVID-19 in Assisted Living Facilities. Depart ment of Health and Human Services; 2020. https://www.cdc.gov/ coronavirus/2019-ncov/hcp/assisted-living.html.

3. McMichael TM, Currie DW, Clark S, et al. Epidemiology of COVID-19 in a long-term care facility in King County, Washington. N Engl J Med. 2020;382(21):2005-2011.

4. Arons MM, Hatfield KM, Reddy SC, et al. Presymptomatic SARS-CoV-2 infections and transmission in a skilled nursing facility. N Engl J Med. 2020;382(22):2081-2090

5. Quality, Safety and Oversight Group at Centers for Medicare and Medicaid Services. Nursing Home Reopening Recommendations for State and Local Offiials, May 18, 2020. Department of Health and Human Services; 2020. https://www.cms.gov/files/document/qso-20-30-nh. pdf. Last accessed July 1, 2020.

6. Division of Nursing Homes/Quality, Safety and Oversight Group/Center for Clinical Standards and Quality. Centers for Medicare and Medicaid. Data from: COVID-19 Nursing Home Data. 2020;2.1. data.cms.gov. May 26, 2020. https://data.cms.gov/stories/s/COVID-19-NursingHome-Data/bkwz-xpvg. Last accessed July 12, 2020.

7. Collier E, Harrington C. Staffing characteristics, turnover rates, and quality of resident care in nursing facilities. Res Gerontol Nurs. 2008; 1(3):157-70.

8. Keeping patients safe: Institute of Medicine looks at transforming nurses' work environment. The Quality letter for healthcare leaders. 2004;16(1):9-11, 1 .
9. Bibbins-Domingo $\mathbf{K}$. This time must be different: disparities during the COVID-19 pandemic. Ann Intern Med. 2020.

10. Dwyer R, Stoelwinder J, Gabbe B, Lowthian J. Unplanned transfer to emergency departments for frail elderly residents of aged care facilities: a review of patient and organizational factors. J Am Med Dir Assoc. 2015;16(7):551-62.

11. Wunderlich GSSF, Davis CK, editors. Institute of Medicine (US) Committee on the Adequacy of Nursing Staff in Hospitals and Nursing Homes. Nursing Staff in Hospitals and Nursing Homes: Is It Adequate. National Academies Press (US); 1996.

12. McMichael TM, Clark S, Pogosjans S, et al. COVID-19 in a long-term care facility - King County, Washington, February 27-March 9, 2020 MMWR Morb Mortal Wkly Rep. 2020;69(12):339-342.

13. Goldsmith T. Short staffing an issue at NC nursing homes marked by COVID-19 outbreaks. North Carolina Health News. 2020. https://www. northcarolinahealthnews.org/2020/04/20/short-staffing-an-issue-atnc-nursing-homes-marked-by-covid-19-outbreaks/ Last accessed July 7, 2020.

14. Grinspan L. Caregiving at a nursing home is a hard job. Coronavirus could make it even harder. Miami Herald. 2020. https://www. miamiherald.com/news/coronavirus/article241329821.html Last accessed June 27, 2020.

15. Castle NG, Ferguson-Rome JC. Influence of nurse aide absenteeism on nursing home quality. Gerontologist. 2015;55(4):605-15

16. Wiesman J, Lofy $\mathbf{K}$. Long-Term Care Facility Director. State of Washington: Department of Health; 2020.

17. Bhatraju PK, Ghassemieh BJ, Nichols M, et al. Covid-19 in critically ill patients in the Seattle region - case series. N Engl J Med. 2020;382(21):2012-2022.

18. Chu HY, Englund JA, Starita LM, et al. Early detection of COVID-19 through a citywide pandemic surveillance platform. N Engl J Med. 2020.

19. Centers for Disease Control. Return to Work Criteria. National Center for Immunization and Respiratory Diseases (NCIRD), Division of Viral Diseases. 2020.

20. Moriarty LF, Plucinski MM, Marston BJ, et al. Public health responses to COVID-19 outbreaks on cruise ships - worldwide, February-March 2020. MMWR Morb Mortal Wkly Rep. 2020;69(12):347-352.

21. Wallace M, Hagan L, Curran KG, et al. COVID-19 in correctional and detention facilities - United States, February-April 2020. MMWR Morb Mortal Wkly Rep. 2020;69(19):587-590.

22. Roxby AC, Greninger AL, Hatfield KM, et al. Outbreak investigation of COVID-19 among residents and staff of an independent and assisted living community for older adults in Seattle, Washington. JAMA Intern Med. 2020.

23. Statistics USBoL. Labor force statistics from the current population survey. www.bls.gov/cps/cpsaat11.htm. Last Accessed July 29, 2020.

24. Webb Hooper M, Nápoles AM, Pérez-Stable EJ. COVID-19 and racial/ ethnic disparities. Jama. 2020.

25. Gausman J, Langer A. Sex and gender disparities in the COVID-19 pandemic. J Women's Health. 2020;29(4):465-466.

26. U.S. Census. U.S. Department of Commerce. https://www.census.gov/ quickfacts/fact/table/seattlecitywashington,US/PST045219 Last Accessed July 16, 2020.

Publisher's Note Springer Nature remains neutral with regard to jurisdictional claims in published maps and institutional affiliations. 